\title{
Design and Implementation of a Modular Bidirectional Switch Using SiC-MOSFET for Power Converter Applications
}

\author{
Edgar Maqueda ${ }^{\mathbb{D}},{ }^{1}$ Jorge Rodas ${ }^{D},{ }^{1}$ Sergio Toledo, ${ }^{2}$ Raúl Gregor, ${ }^{1}$ David Caballero, ${ }^{1}$ \\ Federico Gavilan, ${ }^{1}$ and Marco Rivera ${ }^{2}$ \\ ${ }^{1}$ Laboratory of Power and Control Systems, Facultad de Ingeniería, Universidad Nacional de Asunción, Luque, Paraguay \\ ${ }^{2}$ Laboratory of Energy Conversion and Power Electronics, Universidad de Talca, Curicó, Chile \\ Correspondence should be addressed to Edgar Maqueda; emaqueda@ing.una.py
}

Received 31 May 2018; Revised 10 September 2018; Accepted 17 September 2018; Published 8 October 2018

Academic Editor: Michele Riccio

Copyright (C) 2018 Edgar Maqueda et al. This is an open access article distributed under the Creative Commons Attribution License, which permits unrestricted use, distribution, and reproduction in any medium, provided the original work is properly cited.

\begin{abstract}
The bidirectional switch (Bi-Sw) is a power device widely used by power conversion systems. This paper presents a novel modular design of a Bi-Sw with the purpose of providing to beginner researchers the key issues to design a power converter. The Bi-Sw has been designed in modular form using the SiC-MOSFET device. The Bi-Sw uses the advantages of SiC-MOSFET to operate at high switching frequencies. The verification of the module is carried out experimentally by means of the implementation in a voltage regulating converter, where performance analysis, power losses, and temperature dissipation are performed.
\end{abstract}

\section{Introduction}

The bidirectional switches (Bi-Sws), also known as fourquadrant switches, can block positive or negative voltages as well as drive currents in any direction $[1,2]$. At present, their cost is high, since they are manufactured to measure depending on the application. The use of Bi-Sws is mainly demanded by power converters. Power converters using Bi-Sw include alternating voltage regulators, voltage source inverters (VSI) [3], converters with back-to-back power storage units [4], and multiples topologies of direct and indirect matrix converters found in the literature [5-8], topics that are of great interest to researchers today. Depending on the aforementioned applications, the Bi-Sws are demanded in different quantities and electrical characteristics. Therefore, a modular Bi-Sw that meets certain electrical and elementary criteria would lead to a contribution of value aimed at researchers who wish to carry out an experimental implementation in power converters.

The Bi-Sw is formed by two main components which are the power semiconductor and the power semiconductor gate driver [9]. Semiconductors used to construct the power circuit in applications such as matrix converters include MOSFETs for low power and high switching frequency applications, semiconductors such as the gate deflection thyristor (GTO), the switching thyristor (IGCT), and MOS deviation thyristor (MTO) for higher power applications but with switching frequency limitations [10]. Nowadays the most used semiconductors in power converters are IGBTs, silicon Si-MOSFET, and silicon carbide SiC-MOSFETs [1114], where the semiconductor with $\mathrm{SiC}$ technology takes advantage in relation to other technologies as Si-IGBT and RB-IGBTs in reference to power losses, dissipated temperature, and switching frequency operating high power and high switching frequencies $[15,16]$. The controllers of the power semiconductor gates are found in research papers formed by push-pull circuits coupled with a previous stage of isolation by means of optocouplers. These circuits present the least cost whereas they need several active components, as transistors, to amplify the control signal generally of about $3 \mathrm{~V}-5 \mathrm{~V}$ to $15 \mathrm{~V}-20 \mathrm{~V}$ [17], and composite gate chips (ICs) of MOSFETs and IGBTs with dual outputs, overcurrent detection, and separation between feeds that can be logic, optical, through optocouplers and capacitive type [18]. The advantage of these ICs is that they reduce the physical size of the active components of the circuit in a single chip because the control functions of the power semiconductors are standard. To improve performance of power converters, it is very important to use $\mathrm{Bi}-\mathrm{Sw}$ with characteristics that approximate 


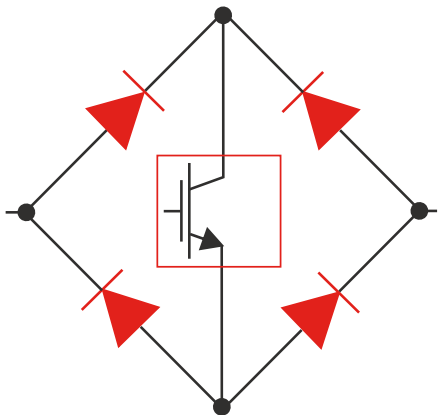

(a)

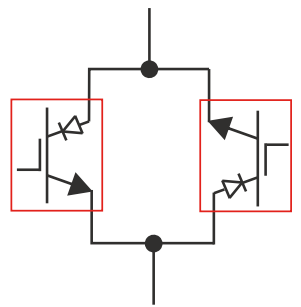

(b)

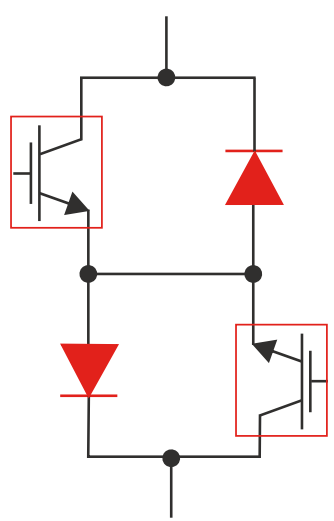

(c)

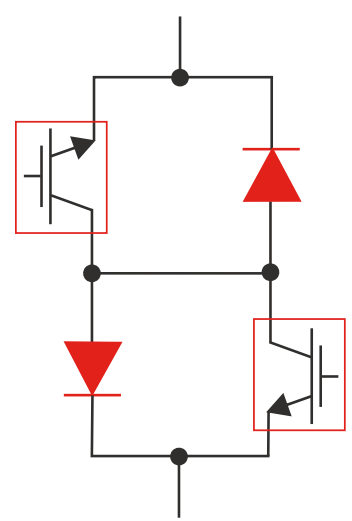

(d)

FIgure 1: Topologies of the Bi-Sw (a) diode bridge with an IGBT arrangement, (b) anti-paralleled reverse blocking IGBTs (RBIGBT) arrangement, (c) common emitter (CE) anti-paralleled IGBT arrangement, and (d) common collector (CC) anti-paralleled IGBT arrangement.

the ideals, which is why technological advances in power semiconductors and gate controllers favor the construction of better power switches, since these are the main components that compose them [19]. The main characteristics that must be possessed by the Bi-Sws applied to the power converters are (i) switching at high frequencies and voltage, (ii) high temperature handling, and (iii) lower power losses.

The modularity of the Bi-Sw circuit would facilitate the implementation of power converters, since it points to its use from simple power converters that require a smaller number of switches, such as the case of the voltage regulating converter, to matrix converter of $n$ quantities of phases, which demand the greater amount of Bi-Sw depending on the number of input or output phases. However, it is anticipated that, unlike custom designs of the Bi-Sw built in a single unit or electronic board for the power converters, the modules of the $\mathrm{Bi}-\mathrm{Sw}$ for the interconnections between each other require the use of multiple connectors and cabling, raising the cost of implementation and also favoring generations of parasitic currents and driving losses due to driver impedances.

This paper presents the design and implementation issues of a modular $\mathrm{Bi}-\mathrm{Sw}$ using $\mathrm{SiC}-\mathrm{MOSFET}$ with the purpose of providing a practical alternative with attractive technical characteristics for the implementation of a power converter, providing the key points for its constructive design. Similar investigations have carried out studies of semiconductor SiC-MOSFET application in the matrix converter $[20,21]$. These works have designed the Bi-Sws according to their applications, and without focusing on the description of their design. The contribution of this article is the design of the $\mathrm{Bi}$ $\mathrm{Sw}$ in a modular form explaining in detail the issues to its design and construction unlike with the articles previously cited, standardizing its use in power converters. Finally, an alternating voltage regulator is implemented experimentally to analyze its performance under frequency and power variations.

The organization of the paper is as follows. Section 2 describes Bi-Sw topology and design. In Section 3 the Bi$\mathrm{Sw}$ is implemented in an ac voltage regulator in order to validate its operation in power converters. Then, in Section 4 the description for the performance evaluation of $\mathrm{Bi}-\mathrm{Sw}$ by analyzing the conduction losses and switching SiC-MOSFET is performed, and finally, the conclusions are summarized in Section 5.

\section{Bi-Sw Topology and Design}

The Bi-Sws are four-quadrant switches that can block voltages and positive and negative drive currents in any direction. Currently there are several commercial Bi-Sws designed for matrix converters. Some of them are made with two quadrants IGBT, MOSFET and the SiC-MOSFET [15], and are configured as follows:

(1) Diode bridge with an IGBT arrangement, Figure 1(a).

(2) Anti-paralleled reverse blocking IGBTs (RB-IGBT) arrangement, Figure 1(b).

(3) Common emitter (CE) anti-paralleled IGBT arrangement, Figure 1(c).

(4) Common collector (CC) anti-paralleled IGBT arrangement, Figure 1(d).

The Bi-Sws formed by arrays of transistors on CE and $\mathrm{CC}$ are commonly used by power converters allowing control of current direction and also these arrangements have lower losses in conduction compared with the $\mathrm{Bi}-\mathrm{Sw}$ with diodes bridge and the IGBT devices with reverse blocking [10].

The Bi-Sw is divided into two modules, a buffer and a power module. The buffer performs signal conditioning for levels of voltage and currents that require power device for proper operation and isolation of the electrical noise. The power module is formed by the SiC-MOSFET to perform the switching of the input ac voltage. Figure 2 shows the block diagram of the Bi-Sw formed by a pulse width modulation (PWM) generator and the modules.

2.1. Buffer Description. The switching devices require a drive signal for their ON and OFF states. In most applications, 


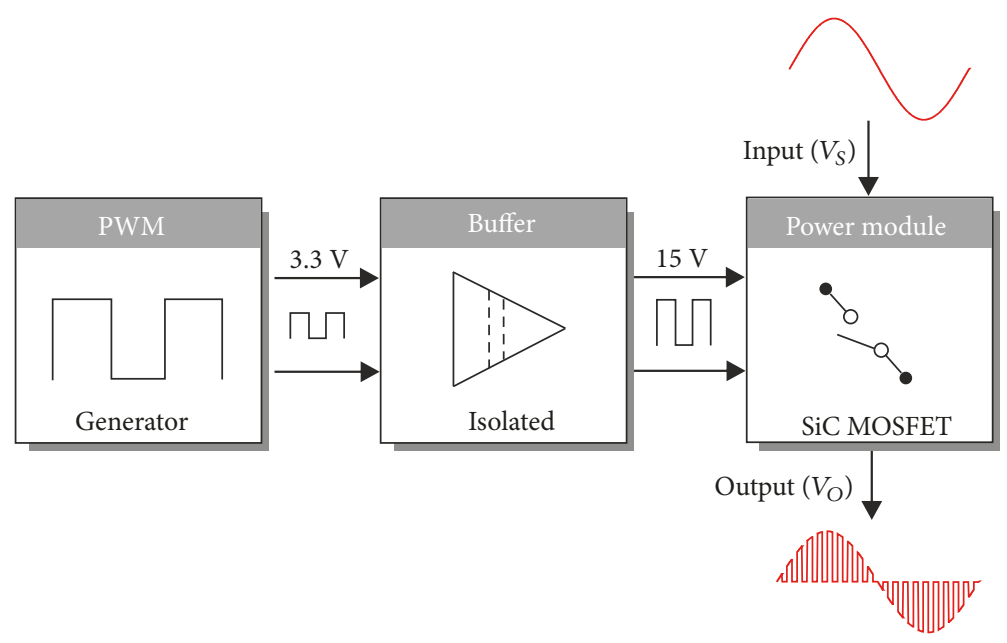

FIgURE 2: Block diagram of the Bi-Sw operation.

TABLE 1: Electrics characteristics of ISO 5500 and IR 2113.

\begin{tabular}{lccc}
\hline Parameter and unit & Symbol & ISO 5500 & IR 2110 \\
\hline Output current (A) & $I_{O}$ & 2.5 & 2 \\
Current load (A) & $I c$ & 150 & 150 \\
Voltage blocking (V) & $V C E$ & 1200 & 600 \\
Propagation delay (ns) & $T_{P L H}, T_{P H L}$ & 300 & 120 \\
Isolated & - & Capacitive & Logic \\
Protection (over-current) & - & Yes & No \\
Protection (under-voltage) & - & Yes & Yes \\
\hline
\end{tabular}

the drive signal is generated by a PWM, developed by control algorithms in microcontrollers, digital signal processor (DSP), or field programmable gate array (FPGA) [22]. The buffer circuit must have the following characteristics:

(1) Use of control driver device whose output electrical characteristics such as voltage, current, and bandwidth are suitable for driving the power device.

(2) Electrical insulation of the feeds (VCC) and ground (GND) of the power device to prevent the spread of electrical noise generated by the power devices.

Taking into account the previously mentioned criteria, a comparison was made between ICs manufactured for the control of power semiconductors, in order to determine the ICs with better electrical characteristics for this application.

The ICs selected in this comparison were ISO 5500 from Texas Instruments [23] and IR 2113 [24] from International Rectifier. Table 1 shows the main characteristics of these ICs. As a result of this comparison, we have chosen to use the ISO 5500 IC because of the ability to control power semiconductors with load current range $I c=150 \mathrm{~A}$ and voltage blocking of $1200 \mathrm{~V}$ where the SiC-MOSFET to be used in the power circuit needs a controller of these characteristics.

When used in conjunction with isolated power supplies, the device blocks high voltage, isolates ground, and prevents noise currents from entering the local ground and interfering with or damaging sensitive circuitry.
It is considered very important in the design to have an electrical separation by means of a physical distance between the control circuit generally formed by the DSP and the FPGA in charge of the switching techniques and the power circuit formed by the Bi-Sw in order to avoid the parasitic currents induced by switching from large powers to very high frequencies. For this reason, we have opted for the integration to the design, of an isolation by means of an optical fiber, which meets this need. The fiber optic kit composed by the family transmitters and receivers HFBR-0500Z was used because of its availability and accessible cost in the market, Figure 3(a).

2.2. Power Module Description. The power module consists of power semiconductors devices. In this case, SiC-MOSFETs forming the Bi-Sw are shown in Figure 3(b), and they are responsible for switching the input voltage. Power transistors are unidirectional devices and then it is necessary to use two transistors to achieve the bidirectional switching. The polarization resistors are specified in Table 2.

The power module was implemented with an $\mathrm{N}$ channel SiC-MOSFET (SCH2080KE) co-packaged with SiC Schottky diode of Rohm Semiconductor. The buffer and power module PCBs were designed in separate forms for the purpose of quick and easy replacement in case of failure of any component of the circuit; it also has benefits to set up a circuit more compact reducing the linear dimension of the PCB. 
TABLE 2: Parameters of the Bi-Sw experimental setup.

\begin{tabular}{lcccccc}
\hline Parameter & $L_{1}$ & $C_{1}$ & $R_{1}, R_{2}$ & $R_{3}, R_{4}$ & $R$ \\
$(\Omega)$ & $(\mathrm{k} \Omega)$ & $\begin{array}{c}R \\
(\Omega)\end{array}$ & $\begin{array}{c}L \\
(\mu \mathrm{H})\end{array}$ \\
\hline Value & $(\mathrm{mH})$ & 2.5 & 10 & 4.7 & 10 & 220 \\
\hline
\end{tabular}

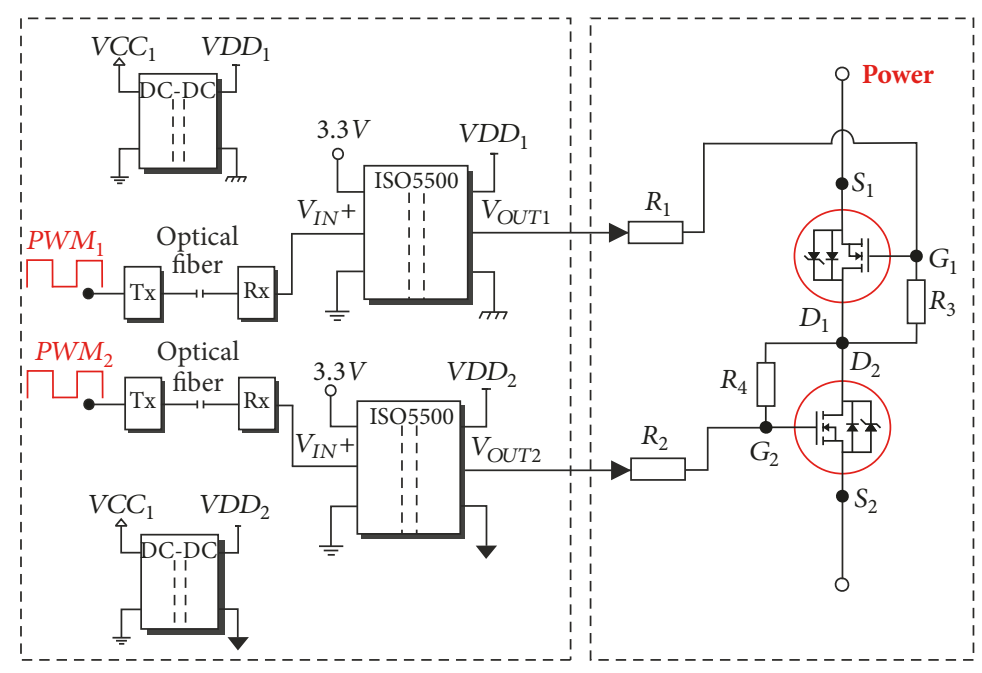

(a)

(b)

FiguRE 3: Electric diagram of Bi-Sw, (a) buffer circuit and (b) power module circuit.

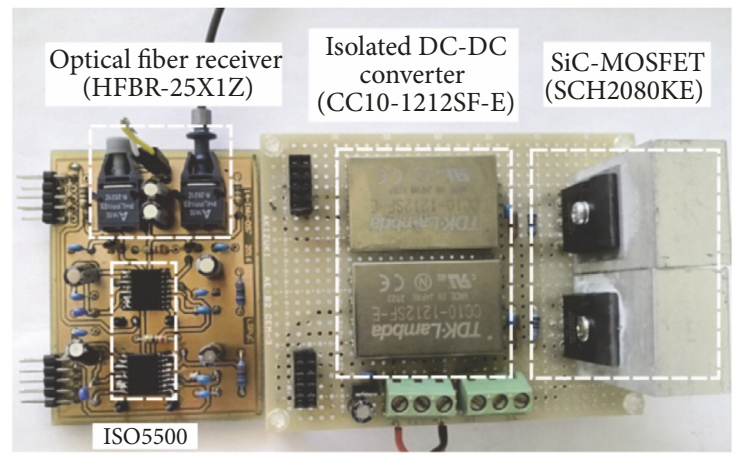

(a)

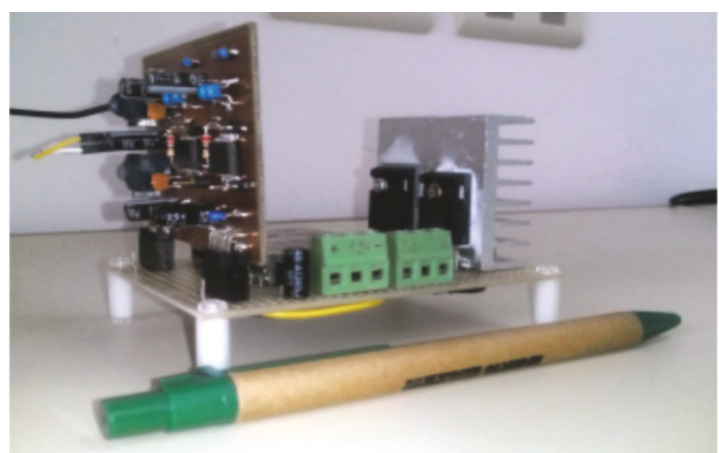

(b)

Figure 4: Images of the Bi-Sw PCB board. (a) Electronic boards for the Bi-Sw, buffer and power module. (b) Final disposition of the Bi-Sw board.

Figure 4 shows the electronic boards (PCB) of Bi-Sw and the integration of both PCB modules.

\section{Implementation of the Bi-Sw in the ac Voltage Regulator}

To validate the correct operation of the Bi-Sw designed with $\mathrm{SiC}$-MOSFETs, an ac voltage regulator has been experimentally implemented. The ac voltage regulators are energy converters that control the power delivered to a given load. In general, the power is controlled by controlling the effective value of the voltage supplied to the load, that is, by varying the duty cycle of the PWM signal.

For this particular study, an ac voltage regulator was constructed using the Bi-Sw module whose circuit final disposition is shown in Figure 4(b). Equation (1) describes the mathematical expression for calculating the output voltage $V_{O}$, where $V_{S}$ is the input voltage and $k$ is the PWM duty cycle in percentage (\%):

$$
V_{O}=V_{S} \sqrt{k}
$$

The electrical circuit diagram of the ac voltage regulator (test circuit) is shown in Figure 5(a), where the source ac voltage $V_{S}$ was $220 \mathrm{~V}$; the load $R, L$ was a group of $100 \mathrm{~W}$ light bulbs connected in parallel, where their impedance values are in Table 2. $V C C_{1}$ is the power supply of the input circuit of the ISO 5500 equal to $3.3 \mathrm{~V}$, and $V D D_{1}$ and $V D D_{2}$ are the power supply of the output circuit of it equal to $15 \mathrm{~V}$. Switching the $\mathrm{Bi}$-Sw generates electrical noise at the input voltage of the grid, which must be avoided. For this purpose low-pass $L C$ 


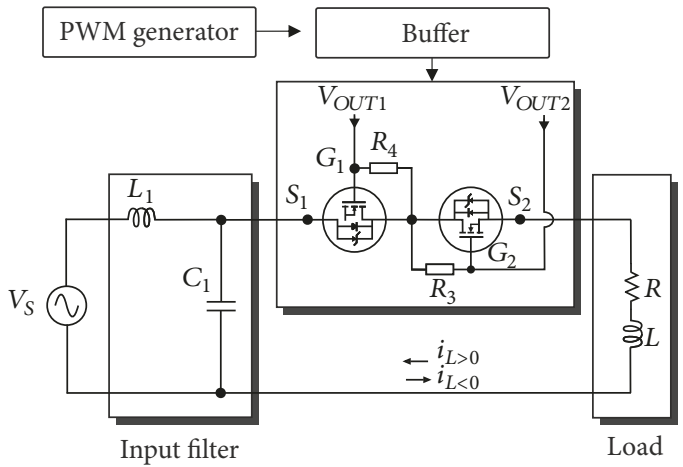

(a)

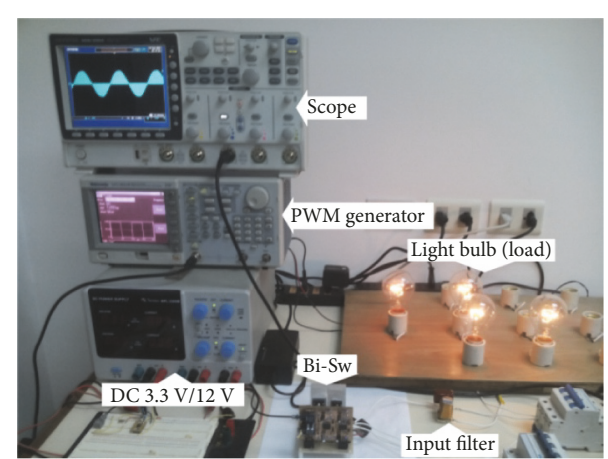

(b)

FIGURE 5: Electrical diagram of the ac voltage regulator and the experimental setup. (a) Electrical diagram of the prototype of ac voltage regulator (test circuit). (b) Experimental setup of the ac voltage regulator.

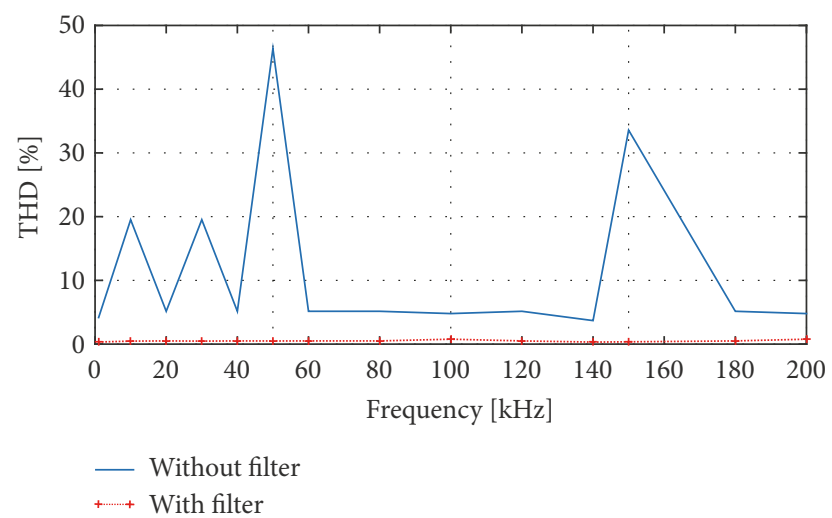

Figure 6: Analysis of the THD measured in $V_{S}$ without filter in the input and with filter in the input.

filters are generally used $[25,26]$. The cutoff frequency of the filter was $200 \mathrm{~Hz}$ lower than the switching frequency. Table 2 shows the parameters of the circuit components.

3.1. Input Filter Evaluation. The switches of the Bi-Sw produce high interference in the input voltage of the voltage regulator converter. To prevent these disturbances in the input voltage, an LC-type filter is integrated into the circuit as shown in Figure 5(a). Experimental results are presented in terms of the total harmonic distortion (THD) of the input voltage without the input filter and with the input filter applied to the circuit at different switching frequencies. Figure 6 shows the obtained results in terms of the THD of the input voltage, where it is observed that the interferences by the switches of the Bi-Sw are attenuated in the order of $0.77 \%$.

\section{Evaluation of Power Losses}

The Bi-Sw performs energy conversion directly through the power transistors. These devices have energy losses, which are generated in the states of switching and conduction of the transistor $[27,28]$. The manufacturer usually provides these data, but the operating points of these measurements differ from the operating points of each specific application; this analysis is recommended to make for this application.

4.1. Switching Losses. Switching losses are originated in the changes of ON-states and OFF-states of the power device. Figure 7 shows the experimental current $i_{L}$, drain voltage $V_{D S}$, and gate voltage $V_{G S}$ of the SiC-MOSFET at a PWM switching frequency $\left(F_{S W}\right)$ equal to $100 \mathrm{kHz}$ measured by a digital oscilloscope. Energy losses $E_{\mathrm{ON}}$ and $E_{\mathrm{OFF}}$ are given by (2) and (3) where $t_{O N}$ and $t_{O F F}$ are the time in ON-states and OFF-states, respectively. $V_{D S}$ is the peak voltage between the drain and the source and $i_{L}$ is the peak current flowing through the SiC MOSFET.

$$
\begin{gathered}
E_{\mathrm{ON}}=\frac{1}{2} t_{\mathrm{ON}} V_{D S} i_{L} \\
E_{\mathrm{OFF}}=\frac{1}{2} t_{\mathrm{OFF}} V_{D S} i_{L} .
\end{gathered}
$$

By using (2) and (3) it is possible to calculate power losses for the commutations, which are given by (4) and (5), where $L_{\mathrm{ON}}$ and $L_{\mathrm{OFF}}$ are the power losses in the ON-states and OFFstates, respectively, and $F_{S W}$ is the switching frequency.

$$
\begin{aligned}
L_{\mathrm{ON}} & =E_{\mathrm{ON}} F_{S W} \\
L_{\mathrm{OFF}} & =E_{\mathrm{OFF}} F_{S W} .
\end{aligned}
$$

4.2. Conduction Losses. The conduction loss is the sum of conduction losses of the MOSFET and the co-packed diode. Instant conduction loss $\left(L_{\mathrm{CON}}\right)$ is directly related to the current through the semiconductor device and its $\mathrm{ON}$-state resistance. This loss is represented by (6) where $r_{d}$ RDS is the drain source ON-state resistance of the MOSFET and $i_{L}$ is the root mean square value (RMS) of current through the device for this case. Then, by (7) the full sum of the power loss $\left(L_{T}\right)$ is calculated. Table 3 presents the results of the losses analysis at $F_{S W}=100 \mathrm{kHz}$ and $i_{L}=6 \mathrm{~A}$. In order to arrive at these results, firstly, we calculate by means of (2) and (3) the power loss by commutation in the ON and 
TABLE 3: Results of the losses analysis at $F_{S W}=100 \mathrm{kHz}$ and $i_{L}=6 \mathrm{~A}$.

\begin{tabular}{llcccc}
\hline Parameter & $\begin{array}{c}E_{\text {ON }} \\
(\mathrm{mJ})\end{array}$ & $\begin{array}{c}E_{\text {OFF }} \\
(\mathrm{mJ})\end{array}$ & $\begin{array}{c}L_{\text {ON }} \\
(\mathrm{W})\end{array}$ & $\begin{array}{c}L_{\text {OFF }} \\
(\mathrm{W})\end{array}$ & $\begin{array}{c}L_{\text {CON }} \\
(\mathrm{W})\end{array}$ \\
\hline Value & 0.254 & 0.673 & 24.5 & 67.3 \\
\hline
\end{tabular}

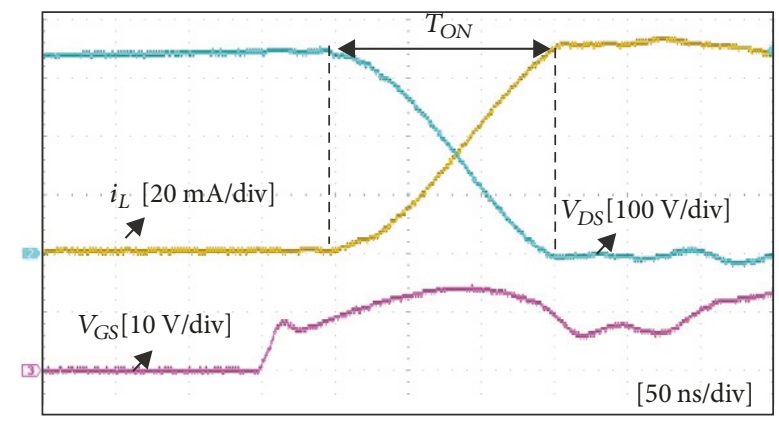

(a)

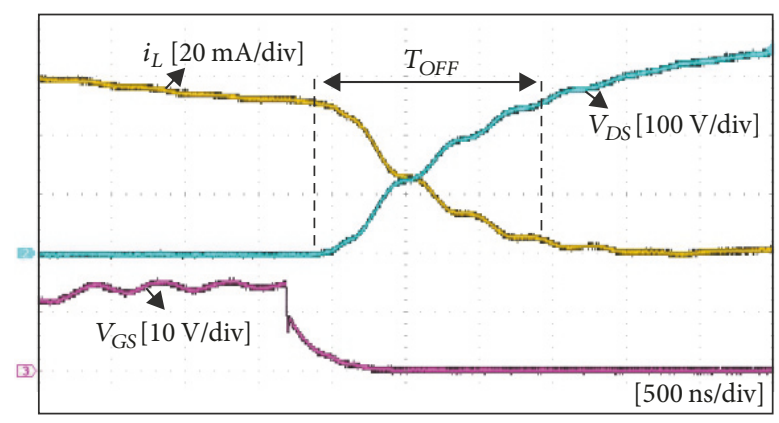

(b)

Figure 7: Experimental switching waveforms of the SiC-MOSFET at $F_{S W}=100 \mathrm{kHz}$. (a) ON-state. (b) OFF-state.

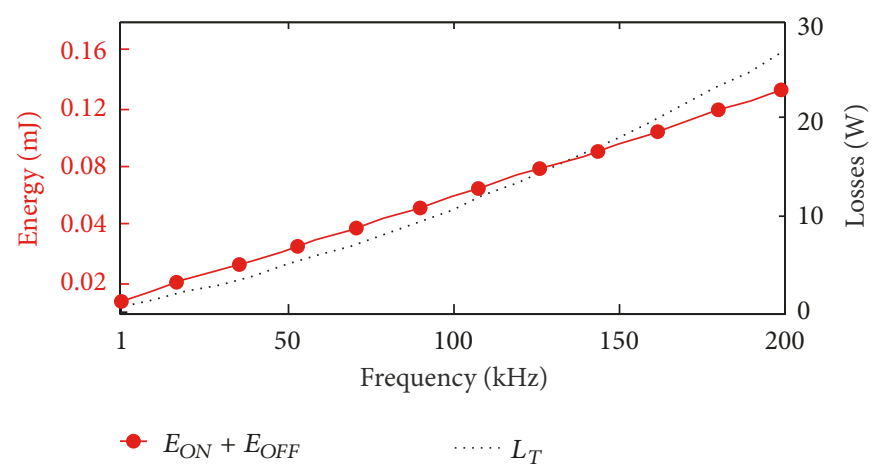

(a)

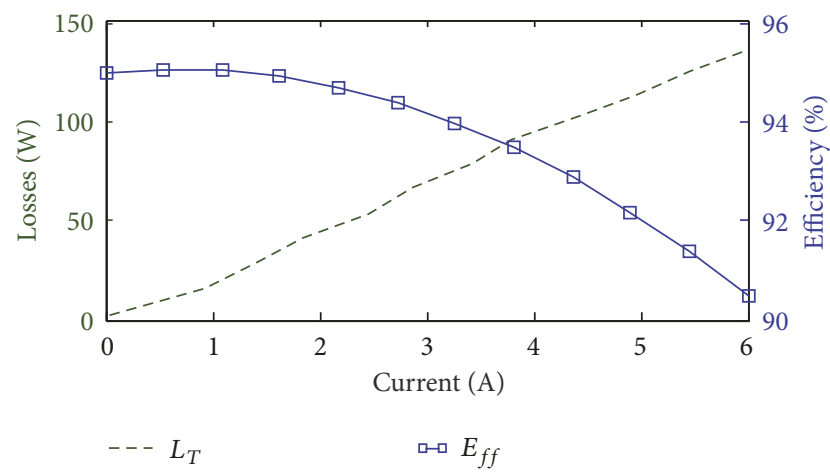

(b)

Figure 8: Energy and power losses evaluations. (a) Energy and power losses curves in relation to the frequency. (b) Power losses and efficiency curves in relation to current in the load.

OFF states of the SiC-MOSFET, where the $T_{O N}$ and $T_{O F F}$ time measurements were previously made (as is shown in Figure 6), using an oscilloscope. Then, by means of (4) and (5), the switching power losses are calculated. On the other hand, the conduction losses are calculated by using (6), where the measurements of the $I_{L}$ current using an oscilloscope are previously made for each case. Finally, through (7) the total power loss is calculated.

$$
\begin{aligned}
L_{\mathrm{CON}} & =\frac{1}{2}\left(r_{d}+R_{D S}\right) i_{L}^{2} \\
L_{T} & =L_{\mathrm{ON}}+L_{\mathrm{OFF}}+L_{\mathrm{CON}} .
\end{aligned}
$$

Figure 8(a) shows the curves of energy and power losses in relation to the switching frequency. The energy losses increase proportionally while increasing switching frequency with minor losses near the cutoff frequency of the filter. Figure $8(\mathrm{~b})$ shows the power losses and efficiency $\left(E_{f f}\right)$ curves of the Bi-Sw, power losses in relation to current in the load and efficiency in relation to the load power maintaining a fixed $100 \mathrm{kHz}$ frequency. The $E_{f f}$ was obtained by the differences of the input power and the power loss by the BiSw; it decreased from $95 \%$ to $90 \%$ when the load current was $0.2 \mathrm{~A}$ to $6 \mathrm{~A}$, light bulb $100 \mathrm{~W}$ to $1200 \mathrm{~W}$, respectively.

The experimental setup is shown in Figure 5(b), where the $\mathrm{Bi}-\mathrm{Sw}$, the load, the power supplies, the PWM generator, and the digital oscilloscope equipped with current and voltage probes are shown. Table 4 shows the comparison of the output voltage values $V_{O}$ calculated by (1) and measured with an oscilloscope on the resistive load connected to the output of the ac voltage regulator in Figure 5.

Figure 9 shows the input voltage waveforms $V_{S}$, the output current $i_{L}$, and the gate voltage $V_{G S}$. The test parameters were $V_{S}=220 \mathrm{~V} \mathrm{AC}, 1 \mathrm{~kW}$ load, and $50 \%$ PWM duty cycle. Figure 9(a) shows the response of the Bi-Sw at $1 \mathrm{kHz}$ switching frequency and Figure 9(b) shows the response at $100 \mathrm{kHz}$ switching frequency.

The Bi-Sw commuted $V_{S}=220 \mathrm{~V} 50 \mathrm{~Hz}$ power supply, with $F_{S W}=100 \mathrm{kHz}$ and $50 \%$ duty cycle. In the Bi-Sw, it is seen that the SiC-MOSFETs are the hottest part at $54.6^{\circ} \mathrm{C}$ in the design, followed by the gate driver ISO 5500 at $31.0^{\circ} \mathrm{C}$. 
TABLE 4: Data of the ac voltage regulator circuit at $F_{S W}=100 \mathrm{kHz}$.

\begin{tabular}{lccc}
\hline $\begin{array}{l}\text { Input voltage } V_{S} \\
(\mathrm{~V})\end{array}$ & $\begin{array}{c}\text { Duty cycle } \\
(\%)\end{array}$ & $\begin{array}{c}\text { Calculated } V_{O} \\
(\mathrm{~V})\end{array}$ & $\begin{array}{c}\text { Measured } V_{O} \\
(\mathrm{~V})\end{array}$ \\
\hline 220 & 25 & 107.8 & 103.0 \\
220 & 50 & 149.6 & 145.1 \\
220 & 75 & 182.6 & 179.7 \\
220 & 90 & 197.8 & 190.0 \\
\hline
\end{tabular}

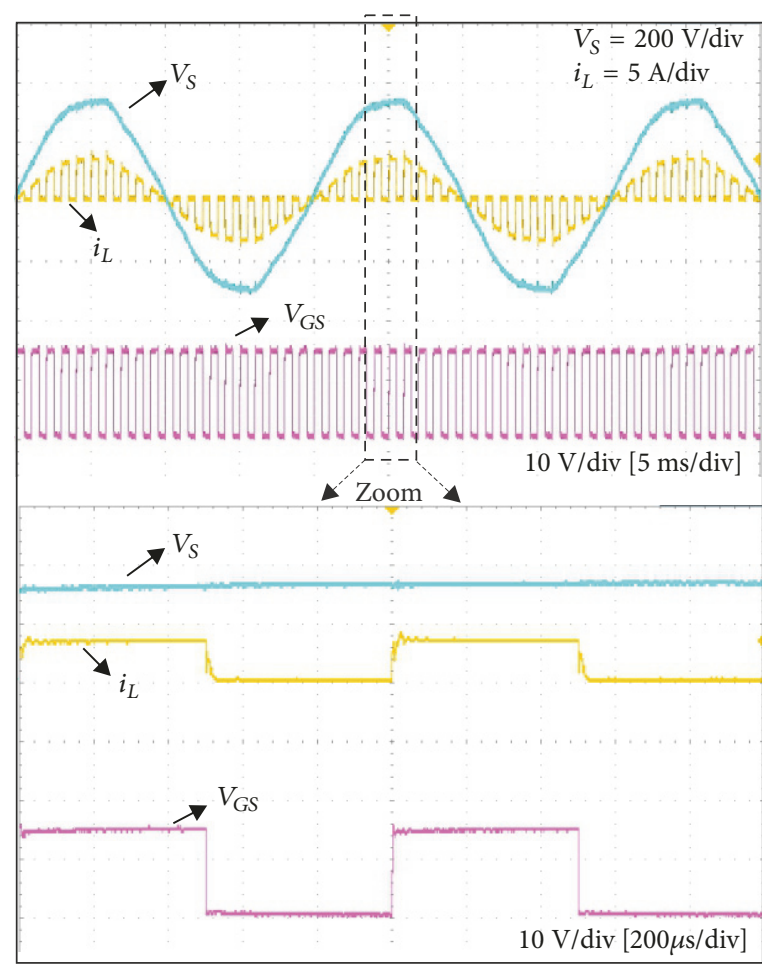

(a)

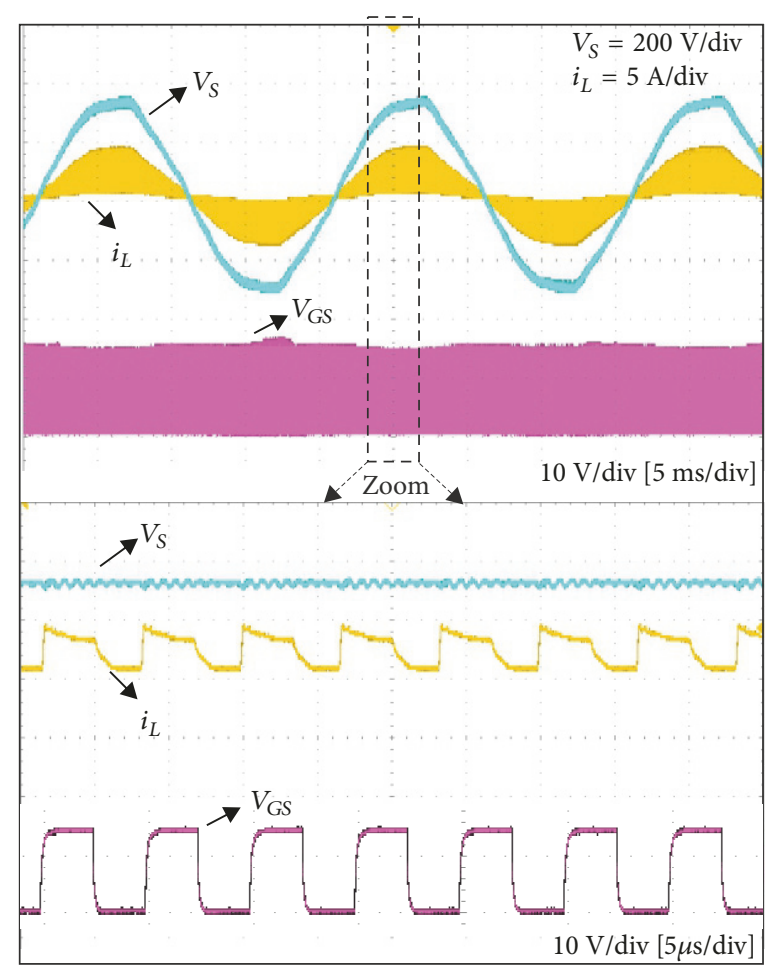

(b)

FIGURE 9: Waveforms of the ac voltage regulator. $V_{S}=220 \mathrm{~V} 50 \mathrm{~Hz}$ power supply, $i_{L}$ output current, and $V_{G S}$ gate voltage at (a) $F_{S W}=1 \mathrm{kHz}$, $50 \%$ duty cycle and (b) $F_{S W}=100 \mathrm{kHz}, 50 \%$ duty cycle.

Thermal tests were also carried out for the system of $\mathrm{Bi}-\mathrm{Sw}$ connected to the ac voltage regulator. A thermal imaging camera FLIR T440 was used. Results are shown in Figure 10.

\section{Conclusion}

In this paper, a detailed design of a novel modular Bi-Sw using very up-to-date technologies in the market is given. Experimental test was performed using a voltage power converter regulator as a case study. Provided results in the ac voltage regulator showed that this Bi-Sw has an excellent operation. The main obtained results were the following: (a) Bi-Sw worked even at a high frequency of $200 \mathrm{kHz}$, helping minimize the components of passive filter in the ac voltage regulator but increase switching losses. (b) Power loss was $25 \mathrm{~W}$ with increasing of the switching frequency of $1 \mathrm{kHz}$ to $200 \mathrm{kHz}, 50 \%$ duty cycle, 2 A load current and $220 \mathrm{~V} 50 \mathrm{~Hz}$ power supply, and $125 \mathrm{~W}$ with increasing of the load current of $0.2 \mathrm{~A}$ to $6 \mathrm{~A}, 100 \mathrm{kHz}$ switching frequency $50 \%$ duty cycle and $220 \mathrm{~V} 50 \mathrm{~Hz}$ power supply. (c) Efficiency decreased from $95 \%$ to $90 \%$ at increased $0.2 \mathrm{~A}$ to $6 \mathrm{~A}$ load current. (d) SiCMOSFETs dissipate average temperature of $54.6^{\circ} \mathrm{C}$.

\section{Data Availability}

Experimental results provided in the article were obtained in the Laboratory of Power and Control Systems, Facultad de Ingeniería, Universidad Nacional de Asunción (Paraguay) in 2018.

\section{Conflicts of Interest}

The authors declare that there is no conflict of interests regarding the publication of this paper. 


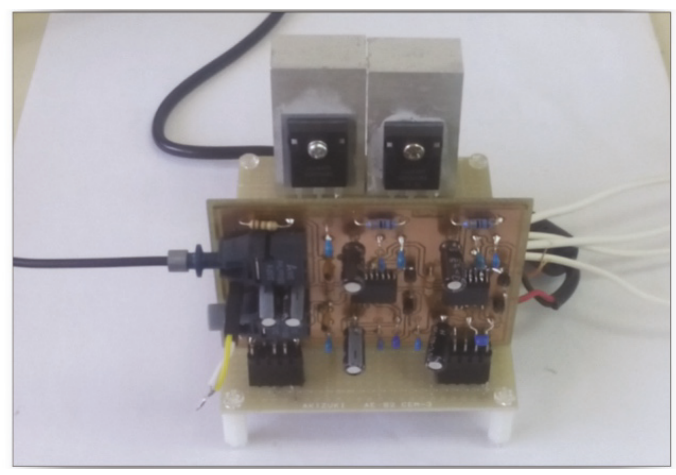

(a)

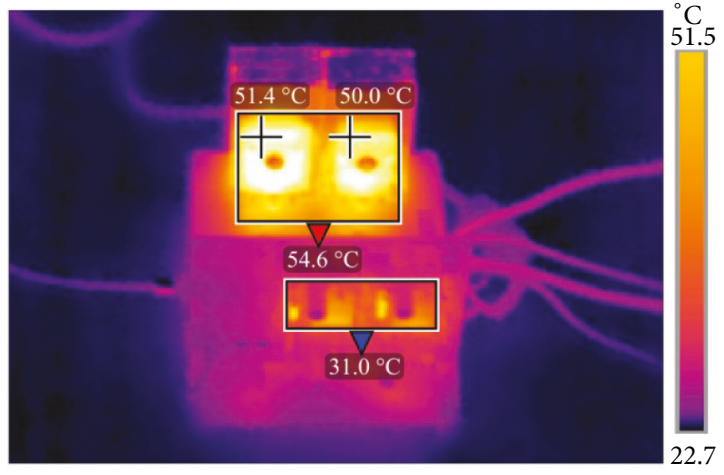

(b)

Figure 10: Thermal image of the Bi-Sw running at $V_{S}=220 \mathrm{~V}, i_{L}=6 \mathrm{~A}, F_{S W}=100 \mathrm{kHz}$, and $50 \%$ duty cycle. The SiC-MOSFETs are shown to be the hottest part at $54.6^{\circ} \mathrm{C}$. (a) Digital image. (b) Thermal image.

\section{Acknowledgments}

This work was supported by the following research projects: CONACYT (Consejo Nacional de Ciencia y Tecnología) by the Projects 14-INV-097 and POSG16-05; FONDECYT (Fondo Nacional de Desarrollo Científico y Tecnológico) (Project 1160690).

\section{References}

[1] J. Jamaludin, N. A. Rahim, and H. W. Ping, "Multilevel voltage source inverter with optimised usage of bidirectional switches," IET Power Electronics, vol. 8, no. 3, pp. 378-390, 2015.

[2] S. Xiong and S.-C. Tan, "Cascaded high-voltage-gain bidirectional switched-capacitor DC-DC converters for distributed energy resources applications," IEEE Transactions on Power Electronics, vol. 32, no. 2, pp. 1220-1231, 2017.

[3] M. Ishigaki, J. Shin, and E. M. Dede, "A Novel Soft Switching Bidirectional DC-DC Converter Using Magnetic and Capacitive Hybrid Power Transfer," IEEE Transactions on Power Electronics, vol. 32, no. 9, pp. 6961-6970, 2017.

[4] M. S. Khan, A. I. Maswood, H. D. Tafti, M. M. Roomi, and M. Tariq, "Control of bidirectional DC/DC converter for back to back NPC-based wind turbine system under grid faults," in Proceedings of the 2016 4th International Conference on the Development in the in Renewable Energy Technology (ICDRET), pp. 1-6, Dhaka, Bangladesh, January 2016.

[5] H. F. Ahmed, H. Cha, A. A. Khan, J. Kim, and J. Cho, "A singlephase buck-boost matrix converter with only six switches and without commutation problem," IEEE Transactions on Power Electronics, vol. 32, no. 2, pp. 1232-1244, 2017.

[6] S. Toledo, E. Maqueda, M. Rivera et al., "Experimental assessment of IGBT and SiC-MOSFET based technologies for matrix converter using predictive current control," in Proceedings of the 2017 CHILEAN Conference on Electrical, Electronics Engineering, Information and Communication Technologies (CHILECON), pp. 1-6, Pucon, Chile, October 2017.

[7] Y. Sun, W. Xiong, M. Su, X. Li, H. Dan, and J. Yang, "CarrierBased Modulation Strategies for Multimodular Matrix Converters," IEEE Transactions on Industrial Electronics, vol. 63, no. 3, pp. 1350-1361, 2016.

[8] E. Maqueda, S. Toledo, R. Gregor et al., "An assessment of predictive current control applied to the direct matrix converter based on SiC-MOSFET bidirectional switches," in Proceedings of the 2017 IEEE Southern Power Electronics Conference (SPEC), pp. 1-6, Puerto Varas, Chile, December 2017.

[9] N. Taïb, B. Metidji, T. Rekioua, and B. Francois, "Novel lowcost self-powered supply solution of bidirectional switch gate driver for matrix converters," IEEE Transactions on Industrial Electronics, vol. 59, no. 1, pp. 211-219, 2012.

[10] L. Empringham, J. W. Kolar, J. Rodriguez, P. W. Wheeler, and J. C. Clare, "Technological issues and industrial application of matrix converters: A review," IEEE Transactions on Industrial Electronics, vol. 60, no. 10, pp. 4260-4271, 2013.

[11] B. Rannestad, A. E. Maarbjerg, K. Frederiksen, S. MunkNielsen, and K. Gadgaard, "Converter monitoring unit for retrofit of wind power converters," IEEE Transactions on Power Electronics, vol. 33, no. 5, pp. 4342-4351, 2018.

[12] J. C. Pacher Vega, J. E. Rodas Benitez, R. I. Gregor Recalde, M. Rivera, A. Renault Lopez, and L. D. Comparatore Franco, "Efficiency analysis of a modular $\mathrm{H}$-bridge based on $\mathrm{SiC}$ MOSFET, International Journal of Electronics Letters, pp. 1-9, 2018.

[13] A. K. Sadigh, V. Dargahi, and K. A. Corzine, "Analytical Determination of Conduction and Switching Power Losses in Flying-Capacitor-Based Active Neutral-Point-Clamped Multilevel Converter," IEEE Transactions on Power Electronics, vol. 31, no. 8, pp. 5473-5494, 2016.

[14] A. Vazquez, A. Rodriguez, M. R. Rogina, and D. G. Lamar, "Different Modular Techniques Applied in a Synchronous Boost Converter with SiC MOSFETs to Obtain High Efficiency at Light Load and Low Current Ripple," IEEE Transactions on Industrial Electronics, vol. 64, no. 10, pp. 8373-8382, 2017.

[15] S. Hazra, A. De, L. Cheng et al., "High Switching Performance of 1700-V, 50-A SiC Power MOSFET Over Si IGBT/BiMOSFET for Advanced Power Conversion Applications," IEEE Transactions on Power Electronics, no. 7, pp. 4742-4754, 2016.

[16] K. Koiwa and J.-I. Itoh, "A Maximum Power Density Design Method for Nine Switches Matrix Converter Using SiCMOSFET," IEEE Transactions on Power Electronics, vol. 31, no. 2, pp. 1189-1202, 2016.

[17] D. Zhou, K. Sun, Z. Liu, L. Huang, K. Matsuse, and K. Sasagawa, "A novel driving and protection circuit for reverse-blocking IGBT used in matrix converter," IEEE Transactions on Industry Applications, vol. 43, no. 1, pp. 3-13, 2007. 
[18] D. Wang, S. Tang, S. Mo et al., "Applicability of single-chip dualgate bidirectional IGBTs in matrix converters," in Proceedings of the 2016 IEEE 8th International Power Electronics and Motion Control Conference (IPEMC 2016 - ECCE Asia), pp. 292-296, IEEE, Hefei, China, May 2016.

[19] S. Hazra, S. Madhusoodhanan, G. K. Moghaddam, K. Hatua, and S. Bhattacharya, "Design considerations and performance evaluation of 1200-V 100-A SiC MOSFET-based two-level voltage source converter," IEEE Transactions on Industry Applications, vol. 52, no. 5, pp. 4257-4268, 2016.

[20] A. Trentin, L. Empringham, L. De Lillo, P. Zanchetta, P. Wheeler, and J. Clare, "Experimental efficiency comparison between a direct matrix converter and an indirect matrix converter using both Si IGBTs and SiC mosfets," IEEE Transactions on Industry Applications, vol. 52, no. 5, pp. 4135-4145, 2016.

[21] S. Safari, A. Castellazzi, and P. Wheeler, "Experimental and analytical performance evaluation of sic power devices in the matrix converter," IEEE Transactions on Power Electronics, vol. 29, no. 5, pp. 2584-2596, 2014.

[22] T. D. Nguyen and H. Lee, "Development of a three-to-fivephase indirect matrix converter with carrier-based PWM based on space-vector modulation analysis," IEEE Transactions on Industrial Electronics, vol. 63, no. 1, pp. 13-24, 2016.

[23] ISO5500 2.5-A Isolated IGBT, MOSFET Gate Driver Data Sheet, Texas Instrument, 2015.

[24] R2110(-1-2)(S)PbF/IR2113(-1-2)(S)PbF, High and Low Side Driver Data Sheet, International Rectifier, 2005.

[25] D. Orser and N. Mohan, "A Matrix Converter Ride-Through Configuration Using Input Filter Capacitors as an Energy Exchange Mechanism," IEEE Transactions on Power Electronics, vol. 30, no. 8, pp. 4377-4385, 2015.

[26] A. K. Sahoo, K. Basu, and N. Mohan, "Systematic input filter design of matrix converter by analytical estimation of RMS current ripple," IEEE Transactions on Industrial Electronics, vol. 62, no. 1, pp. 132-143, 2015.

[27] A. K. Sadigh, V. Dargahi, and K. Corzine, "Analytical determination of conduction power loss and investigation of switching power loss for modified flying capacitor multicell converters," IET Power Electronics, vol. 9, no. 2, pp. 175-187, 2016.

[28] R. Moghe, R. P. Kandula, A. Iyer, and D. Divan, "Losses in medium-voltage megawatt-rated direct $\mathrm{AC} / \mathrm{AC}$ power electronics converters," IEEE Transactions on Power Electronics, vol. 30, no. 7, pp. 3553-3562, 2015. 


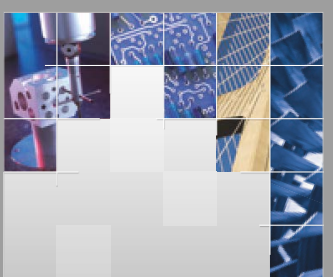

\section{Enfincering}
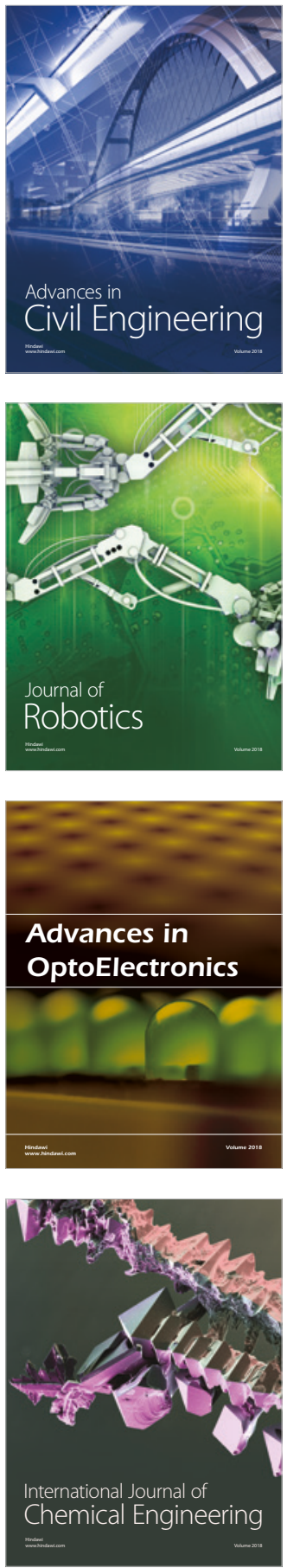

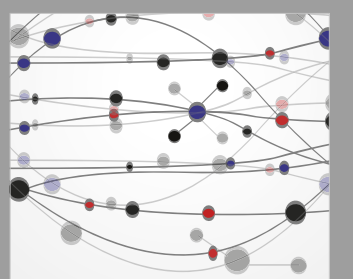

\section{Rotating \\ Machinery}

The Scientific World Journal

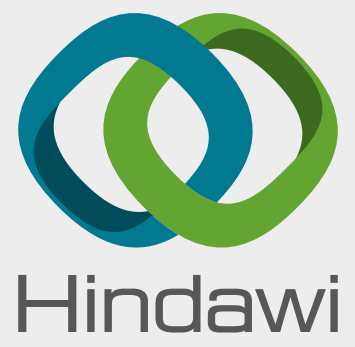

Submit your manuscripts at

www.hindawi.com
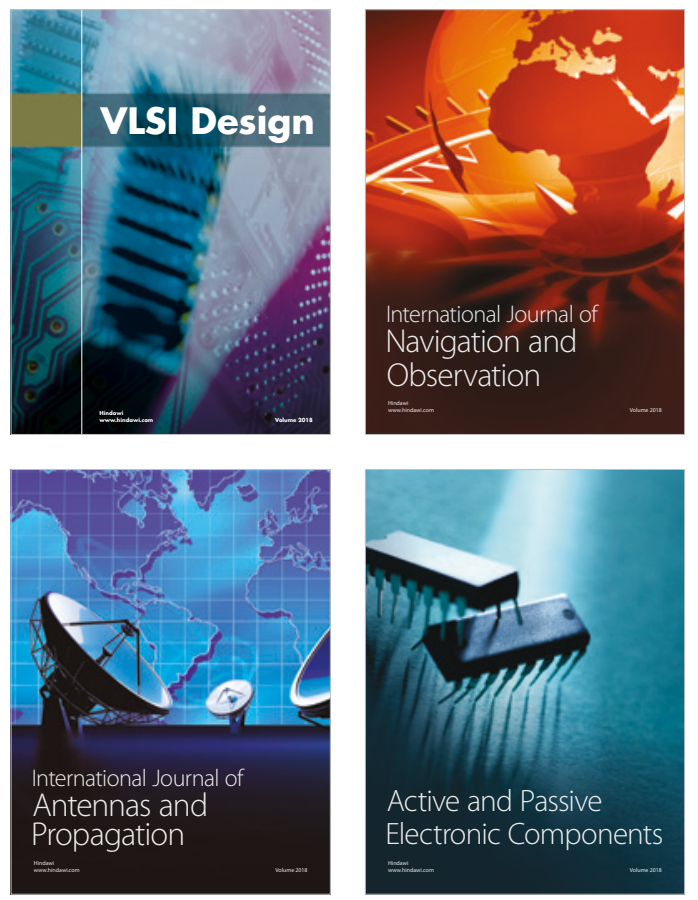
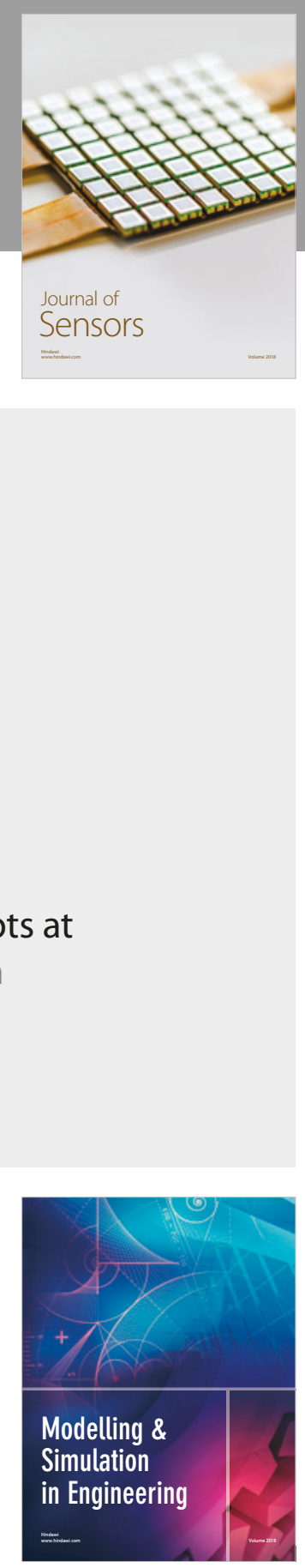

\section{Advances \\ Multimedia}
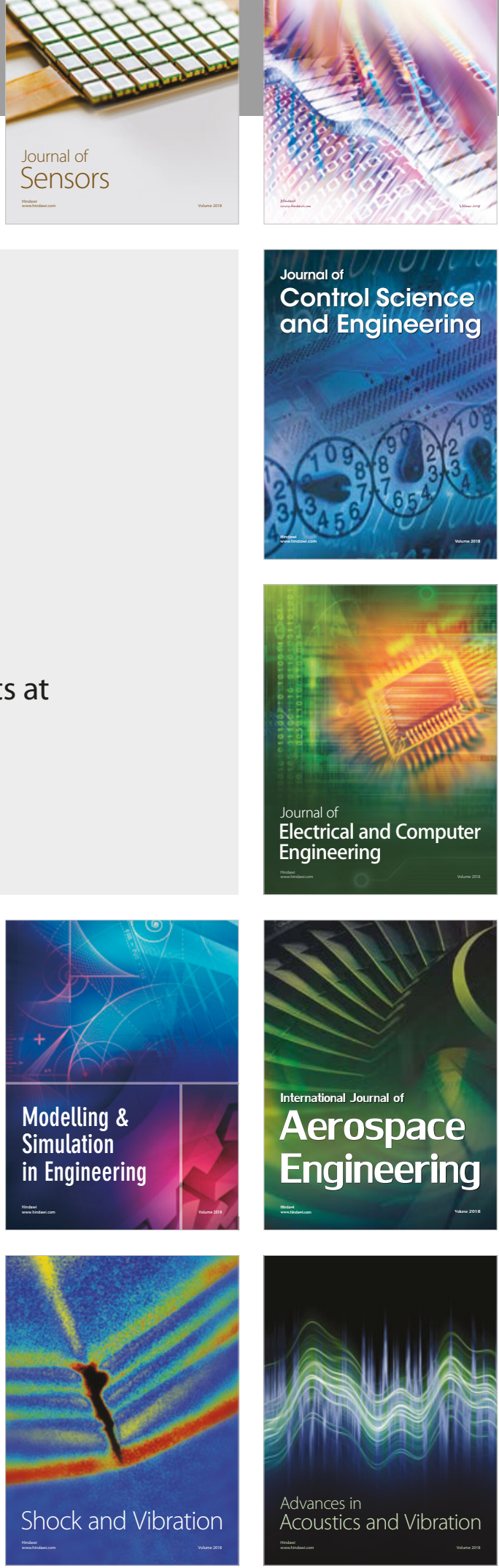